\title{
Impact of GUI personalization of a word processor on a learning activity course
}

\author{
Arnaud Zeller, Pascal Marquet
}

Faculty of Education and Lifelong Learning - LISEC, University of Strasbourg, France.

\begin{abstract}
This research investigates the impact of an activity of personalization of a graphical user interface by the learners, on their behavior of using the ILE. The analysis conducted is based on an exploitation of the interaction traces between the learner and the interface of a word processor software with advanced personalization and auto-writing features including training of spelling and a learning analytics management module. The results show that, several variables related to the facilitation conditions recognized by the ILE partly explain the writing activity. Navigation variable can be correlated with the knowledge of customization possibilities. If the automatic sentence generator has no significant effect on the number of misspellings found in the documents submitted, the intention to personalize the interface seems to have a greater effect than the act of personalization itself. But the impact of the personalization process on learning outcomes is still to be established.
\end{abstract}

Keywords: UTAUT model, ILE, adaptation, word processor, learning analytics, user interface, activity, flexibility 


\section{Introduction}

The question of personalization of learning is a central topic in the field of research on interactive learning environment (ILE). If the digital environments are today, from the point of view of the system (Dillenbourg \& Chounikine, 2007) more and more functional, the question of their adoption by the learners remains posed despite the efforts and means of educational engineering made. In the absence of ease and speed of their handling, the increase in functionality generally implemented makes it possible to adapt usage trajectories that are often thwarted by the emergence of instrumental conflicts (Marquet, 2011). The development of adaptive systems and intelligent tutors (Aleven et al., 2015) does not allow learners to escape the process of instrumental genesis (Rabardel, 1995) (Peraya 2018), a process in which we believe that the interface of the ILE is decisive.

In this paper, we are interested in the question of the role and effect of graphical interfaces in the learning activity course and the impact it has in spelling that we observe through learning analytics. Our work is based on the idea that on the ILE, the appearance and the behavior of metaphorical objects triggering actions and dependent on the graphical interface of the operating system, can be factors of acceptance of the digital environment but can modify the the very purpose of the activity. This research is the second stage of our research that we have started in 2018 with a first stage focusing on the adoption intent with the personalization of a graphical user interface with 50 users (Zeller \& Mohib, 2019). We now expand it to the learning outcomes aspect, considering the first significant results we obtained.

\section{Literature review}

\subsection{UTAUT and user}

Many studies have been conducted on the adoption of a product or technology, particularly in the HMI (Human Machine Interface) community. However, most studies remain focused on the evaluation of functional specifications of a product leaving aside the evaluation of cognitive and psychological aspects. In this respect, the notions of acceptability and intention of use complete the purely functional evaluation.

Barcenilla and Bastien (2009) define the term of acceptability as the degree of integration and appropriation of an object in a context of use. The adoption intent that influences and predicts individual behavior (Venkatesh et al., 2008) is a prerequisite for use behavior in reference to Venkatesh's Unified Technology Acceptance Theory (UTAUT). According to this model, seven constructs were defined as significant determinants of adoption intent and grouped into four factors: 1) the expectations in terms of effort associated with the degree of facility associated with the use of the system; (2) the performance expectations 
associated with the degree to which an individual believes that use of the system will help him achieve a goal; 3) the social influence associated with the degree to which an individual perceives that people who are important to him believe that he or she should use the new system; and 4) the enabling conditions associated with the degree to which an individual perceives that an organization and a support, a help, exist to help him in the use of the system. Four moderating variables were added: age, sex, experience and voluntarism. We use the UTAUT model because of the high number of constructed allowing a high explanatory power of the intention to use a technology.

\subsection{Graphical user interface and learning analytics}

An interface is intended to allow humans to communicate with the machine to perform one or more tasks on a computer that implements processes to achieve it. First represented in the form of an online order, the interfaces have become graphical, relying still today on the metaphor of the office with windows, icons, menus and pointing actions (WAMP).

Our review of literature leads us to consider the process of appropriating a graphical interface of an ILE as a factor contributing to adoption intentions. This process can be revealed by the analysis of differentiated traces according to four types of activity carried out on the software which are the personalization of the interface, the navigation in the software, the formatting and text editing. It aims to characterize the effect of one of the variables of the UTAUT model, namely the enabling conditions of an environment, by establishing its intersection with two of the other three explanatory variables of this model, namely performance expectations and expectations effort. Venkatesh (2008) defines facilitation conditions as "the degree to which an individual believes that a technical and organizational infrastructure exists in support of the use of the system". We call the graphical interface of technical infrastructure linking the educational part and the system part of the ILE. Our study relies on Learning Analytics that is on the collection of digital traces left by the learners on the ILE, which once exploited, make it possible to improve them and facilitate the (Tempelaar et al., 2012), using predictive modeling (Aguilar et al., 2015) or explanatory modeling (Lan et al., 2014).

\section{Methodology}

\subsection{Writing and spelling}

According to Amadieu and Tricot (2006) textual learning involves activities of comprehension, memorization and inference production. We have developed a word processer, Docyrus, with advanced customization functions, justified by the central place occupied by this type of software in the office suites and whose purposes and the interfaces 
on which they are based are plural and multi-forms. We have enhanced the ability of the learner to highly personalize Docyrus interface at any time of the activity.

Word processors can be facilitating instruments for writing invention for purposes of creation, revision or even memorization. It places the student in a continuous interaction with the machine (Bruillard, 2016) with the purpose of modifying students writing skills (Delbrassine, 2018). But learning can take a long time (Nivat, 1985) depending on the level of mastery targeted. Writing stories and tales, even with automated processes, reports requires high writing skills that can to some extent dampen as "the productions that result from it are rarely entirely new" (Ward, 1995). We have implemented in Docyrus an autowriting module which can generate sentences from key words to help the learner write phrases of its story. Some of those sentences have words that need to be granted in gender and number to advance learners in their spelling. Docyrus detects and saves errors relying on its learning analytics module (Leijten, M., Van Horenbeeck, E., \& Van Waes, L., 2015) and offers the student to correct them.

\section{The research}

\subsection{Facilitation conditions of ILE and learning outcomes in reports writing}

In our research, we consider the possibility of customizing an interface from the point of view of its flexibility as one of the facilitation conditions contributing to the adoption intention and otherwise the learning outcomes. We try to answer the following research question : which variables from the ILE ownership process explain the course of a learning activity? Our general assumption is that there is a correlation between the learner's knowledge of possible interface customization actions and the course of the learning activity on the ILE due to the impact of the navigation in the ILE from the interface.

We also hypothesize that the knowledge by the learner, at a certain time of the activity, of the possibilities of personalizing the interface, act as a dissonant element with the prescribed task, thus producing a disturbing effect on the expected actions. In this sense, we consider that text formatting actions differ from writing.

\subsection{Sample and procedure}

The research actually took place during the French Fête de la Science at Strasbourg University in September 2019. 177 participants were asked during thirty minutes to using a new word processor - Docyrus - instead of their familiar word processor to write a short story. On clicking on the start button, and without any information on the steps of the training sequence being given to the users, they quickly navigated step by step to implement the functional blocks necessary for the use of word processor and the writing of their story along with having to deal with spelling suggestions. The challenge was get zero 
spelling errors as some of those sentences that Docyrus auto-generated needed sometimes to be corrected in gender and number. The actions necessary for carrying out the activity required the learner to navigate between the different tabs of the interface ribbon. At the end of the workshop, participants submitted one archive file that contained two files. The first one was the text file that could be analysed to identify spelling mistakes. The second one was a spreadsheet file wich contained learning analytics. Each event generated by the student's use of the keyboard or mouse was captured in real time in Docyrus and time stamped in thousandths of a second. We retained a final sample of 65 measurements due to incomplete activities that stopped suddenly and lasted less than 10 minutes. We measured 6 variables : V1 Show_GUI_Form - sum of opening the interface customization screen actions, V2 Navigation_actions - sum of navigation actions, V3 Text_formating - sum of text formatting actions, V4 sum of insertion images actions in support of story writing, V5 sum of auto-writing actions, V6 sum of spelling errors. We present below the significant results we have obtained.

\section{Results}

2719 actions were recorded, each one consisting of multiple logs. We used Spearman's Rho since some variables do not follow a normal distribution. The results (table 1) analysed in SPSS show a correlation between the learner's knowledge of possible interface customization actions and the realization of the learning activity on the ILE.

Table 1. Correlation between knowledge of possible personalization and navigation actions M-F

\begin{tabular}{l|l|r|r}
\hline \multicolumn{2}{l|}{} & V1_Show_GUI_Form & V2_Navigation_actions \\
\hline $\begin{array}{l}\text { Spearman's } \\
\text { rho }\end{array}$ & Correlation Coefficient & 1.000 & $\mathbf{. 4 4 7 ^ { * * }}$ \\
\hline & Sig. (2-tailed) &. & .000 \\
\hline & N & 65 & 65 \\
\hline
\end{tabular}

Table 2. Correlation between knowledge of possible personalization and navigation actions - $M$

\begin{tabular}{l|l|r|r}
\hline \multicolumn{2}{l|}{} & V1_Show_GUI_Form & V2_Navigation_actions \\
\hline $\begin{array}{l}\text { Spearman's } \\
\text { rho }\end{array}$ & Correlation Coefficient & 1.000 & $\mathbf{. 4 9 4}$ \\
\hline & Sig. (2-tailed) &. & .003 \\
\hline & $\mathrm{N}$ & 34 & 34 \\
\hline
\end{tabular}


Table 3. Correlation between knowledge of possible personalization and navigation actions - F

\begin{tabular}{l|l|r|r}
\hline \multicolumn{2}{l|}{$\begin{array}{l}\text { Spearman's } \\
\text { rho }\end{array}$} & V1_Show_GUI_Form & V2_Navigation_actions \\
\hline & Correlation Coefficient & 1.000 & $\mathbf{. 4 3 7 ^ { * * }}$ \\
\hline & Sig. (2-tailed) &. & .014 \\
\hline & $\mathrm{N}$ & 31 & 31 \\
\hline
\end{tabular}

In addition, a differentiation of the results by gender (table 2 and table 3 ) can be established as many studies based on the UTAUT model had previously established. Indeed, the significance of the correlation is greater in the male $(\mathrm{p}<0.01)$ gender than the female gender $(\mathrm{p}<0.05)$.

Table 4. Correlation between knowledge of possible personalization and text formating - M-F

\begin{tabular}{l|l|r|r}
\hline \multicolumn{2}{l|}{} & V1_Show_GUI_Form & \multicolumn{2}{c}{ V3_Text_formating } \\
\hline $\begin{array}{l}\text { Spearman's } \\
\text { rho }\end{array}$ & Correlation Coefficient & 1,000 & $\mathbf{3 3 3}^{* * *}$ \\
\hline & Sig. (2-tailed) & . &, 004 \\
\hline & $\mathrm{N}$ & 65 & 65 \\
\hline
\end{tabular}

Also, text formatting actions (V3_Text_formating) can be correlated with knowledge of the possibilities (V1_Show_GUI_Form) for customizing the interface (table 4) (p < 0.01) unlike other actions such as inserting an image (variable 4). We find no correlations between the auto-writing generator (V5) and the sum of spelling errors (V6) found in the documents.

\section{Discussion}

The results correlate the visualization of possible interface customization options with navigation in the software. The gender variable is a moderating variable as in the UTAUT model. But we did not find any correlation with the age variable. Likewise, a correlation could not be established between the interface customization actions and the navigation. Similarly, the passage to the act of personalizing the interface after consulting the options proposed in the personalization screen, is not established. With reference to Sperandio's (2008) work on systems ergonomics, we understand this refusal to personalize as the learner's fear of "losing control of his actions" on the ILE. The correlation between the text formatting actions and the consultation of the interface personalization screen which both divert the learner from his main editorial activity can be compared to the Hélices model 
(Linard, 2001). This model of activity connects the double hierarchical and sequential management of the course of action. It poses the central role of the anticipated image of the goal and of the evaluation tests which play the role of compass in the self-control of the action. In our result we understand the interface as a possible revealer of some of the multiple criteria of intentional control: cognitive (perceptions, goals, strategies and plans), psycho-socio-affective (dispositions, attitudes, norms, values and conflicts) and temporal.

\section{Conclusion}

In this study, we evaluate the impact of learner personalization of a word-processing interface on their behavior of using the ILE. The results show that the knowledge of customization possibilities can be correlated with the navigation and the text formatting variables. These correlations are gendered with greater significance for males. But the knowledge of those possibilities can also divert the learner from his main activity, such as implementing formating text actions instead of writing. The interface as a link between the learner and the environment in order to facilitate interactions can also hinder the progress of the activity. In that sense, the impact of the personalization process on learning outcomes remains to be established.

\section{References}

Aleven, V., McLaren, B. M., Sewall, J., Van Velsen, M., Popescu, O., Demi, S., ... \& Koedinger, K. R. (2016). Example-Tracing tutors: Intelligent tutor development for non-programmers. International Journal of Artificial Intelligence in Education, 26(1), 224-269.

Amadieu, F., \& Tricot, A. (2006). Utilisation d'un hypermédia et apprentissage: deux activités concurrentes ou complémentaires?. Psychologie française, 51(1), 5-23.

Barcenilla, J., \& Bastien, J.-M.-C., (2009). « L'acceptabilité des nouvelles technologies : quelles relations avec l'ergonomie, l'utilisabilité et l'expérience utilisateur ? », Le travail humain, 2009/4 Vol. 72, p. 311-331

Bruillard, É. (2016). Quelle informatique à repenser et à construire pour les élèves de l'école primaire?. L'école primaire et les technologies informatisées. Des enseignants face aux TICE, 29-37.

Bush, V. (1945). "As We May Think" in Greif, I. Ed. (1988). Computer-Supported Cooperative Work: A Book of Readings. Morgan Kaufmann, pp 17-34.

Delbrassine, D. (2018). Outils numériques et didactique de l'écriture: Travailler les textes sans fin?. Le francais aujourd'hui, (4), 125-134.

Dillenbourg, P. \& Tchounikine, P. (2007). Flexibility in macro-scripts for computersupported collaborative learning. Journal of Computer Assisted Learning, 23(1), 1-13. 
Gómez-Aguilar, D. A., García-Peñalvo, F. J., Therón, R., \& Conde-González, M. Á. (2015). Exploring Software Engineering Subjects by Using Visual Learning Analytics Techniques.

Lan, A. S., Waters, A. E., Studer, C., \& Baraniuk, R. G. (2014). Sparse factor analysis for learning and content analytics. The Journal of Machine Learning Research, 15(1), 1959-2008.

Linard, M. (2001). Concevoir des environnements pour apprendre: l'activité humaine, cadre organisateur de l'interactivité technique.

Marquet, P. (2011). e-Learning et conflit instrumental. Entre didactique, pédagogie et technique. Recherche et formation, (68), 31-46.

Nivat, M. (1985). Sur l'enseignement de l'informatique liée à des applications. Revue de l'EPI (Enseignement Public et Informatique), 39, 51-54. https ://www.epi.asso.fr/fic_pdf/b39p051.pdf

Peraya, D. (2018). Technologies et formes éducatives: entre rupture et continuité, stabilité et évolution. Distances et médiations des savoirs. Distance and Mediation of Knowledge, (24).

Rabardel, P. (1995). Les hommes et les technologies; approche cognitive des instruments contemporains (p. 239). Armand Colin.

Sperandio, J. C. (2008). L'humain au coeur des systèmes et de leur développement: quelle évolution en 20 ans dans le développement des systèmes. Ergoia. Biarritz, ESTIA.

Sutherland, I. (1963). "Sketchpad: A Man-Machine Graphical Communication System". In proceedings of the Spring Joint Computer Conference, pp 329-346.

Tchounikine, P. (2009). Précis de recherche en ingénierie des ILE.

Tempelaar, D. T., Heck, A., Cuypers, H., van der Kooij, H., \& van de Vrie, E. (2013). Formative assessment and learning analytics. In Proceedings of the third international conference on learning analytics and knowledge (pp. 205-209). ACM.

Venkatesh, V., Brown, S.A., Maruping, L.M., \& Bala, H., (2008). "Predicting Different Conceptualizations of System Use: The Competing Roles of Behavioral Intention, Facilitating Conditions, and Behavioral Expectation”, MIS Quarterly, Vol.32, n³, p. 16 483-502.

Ward, T.B., (1995). - Structured imagination : The role of category structure in exemplar generation, Cognitive Psychology, 27, 1994, p. 1-40.

Zeller, A., \& Mohib, N. (2019). Impact de la personnalisation d'une interface graphique sur l'intention d'adoption d'un EIAH. In Julien Broisin, Eric Sanchez, Amel Yessad, Françoise Chenevotot (Éd.), Actes de la 9ème conférence EIAH (Environnements Informatique pour l'Apprentissage Humain), (pp. 319-330). 